\title{
Distributed fiber optic monitoring of a CFA pile with a central reinforcement bar bundle
}

\author{
Yi RUI ${ }^{\mathbf{a}^{*}}$, Nicholas de BATTISTA ${ }^{\mathrm{a}}$, Cedric KECHAVARZI ${ }^{\mathrm{a}}$, Xiaomin XU ${ }^{\mathrm{a}}$, Mei YIN ${ }^{\mathrm{b}}$ \\ ${ }^{a}$ Centre for Smart Infrastructure and Construction, Department of Engineering, University of Cambridge, Cambridge CB2 ITN, UK \\ ${ }^{b}$ Department of Engineering, University of Cambridge, Cambridge CB2 ITN, UK \\ *Corresponding author. E-mail: ruiyi1123@gmail.com
}

(C) The Author(s) 2021. This article is published with open access at link.springer.com and journal.hep.com.cn

\begin{abstract}
In this paper, we present an application of distributed fiber optic sensor (DFOS) technology to measure the strain of a continuous flight auger (CFA) test pile with a central reinforcement bar bundle, during a static load test carried out in London. Being distributed in nature, DFOS gives much more information about the pile performance as compared to traditional point sensors, such as identifying cross-sectional irregularities or other anomalies. The strain profiles recorded along the depth of the piles from the DFOS were used to calculate pile deformation (contraction), shaft friction, and tip resistance under various loads. Based on this pile load test, a finite element (FE) analysis was performed using a one-dimensional nonlinear load-transfer model. Calibrated by the shaft friction and tip resistance derived from the monitored data, the FE model was able to simulate the pile and soil performance during the load testing with good accuracy. The effect of the reinforcement cage and central reinforcement bar bundle were investigated, and it was found that the addition of a reinforcement cage would reduce the pile settlement by up to $20 \%$.
\end{abstract}

KEYWORDS continuous flight auger pile, static load test, central reinforcement bar bundle, distributed fiber optic sensor, finite element, load transfer

\section{Introduction}

The pile load test is a well-established technique for validating foundation design in general, as well as for proving the suitability of a specific pile design based on site investigation before construction. Due to the crucial importance of this technique in pile construction, Clause 7.5 of Eurocode 7 lays down requirements for preconstruction pile load testing [1] to eliminate potential uncertainties in the pile design, such as soil properties and construction influences. On the other hand, in practice, it has been found that there are still some uncertainties about the interpretation of test results due to the limitations of instrumentation. Conventional instrumentation includes electric resistance and vibrating wire strain gauges, accelerometers, axial load cells, and extensometers [2-7]. Recent advances make use of fiber optic sensors (FOS), based on either Rayleigh, Raman, and Brillouin scattering or Bragg diffraction, as an alternative to traditional

Article history: Received Aug 25, 2018; Accepted Jan 4, 2019 instruments in piles [8]. Thanks to the successful implementation of FOS in many pile load tests in the UK, it is now included alongside conventional instrumentation in the specification guidelines for piling and embedded retaining walls [9].

Commonly used FOS in structural health monitoring are based on either fiber Bragg gratings (FBG) [10-13], Brillouin optical time-domain analysis (BOTDA) [14-18], or Brillouin optical time-domain reflectometry (BOTDR) [19-24]. BOTDR-based distributed fiber optic sensing (DFOS) technology measures changes in strain and temperature using back-scattered light along the entire length of fiber optic cables at a high spatial density. Hence, in pile load tests, DFOS has a distinct advantage over conventional sensor technologies or even FBG, due to its capacity to provide spatially quasi-continuous data, and hence enable the localization of anomalies along the pile depth. DFOS also provides an opportunity to examine in more detail the soil behavior and pile-soil interactions during the pile load test.

This paper deals with the pile testing instrumentation of 
a cast-in situ reinforced concrete pile with a central reinforcement bar bundle. This pile was constructed using the continuous flight auger (CFA) method, and DFOS (BOTDR) was used to supplement traditional pile testing instrumentation. The added value that DFOS technology can bring is demonstrated with extracts from the monitoring data during the static load test. The pile displacement, strain and load transfer behavior were simulated by a simple one-dimensional (1D) load transfer finite element (FE) analysis. Finally, the effects of the central reinforcement bar bundle and reinforcement cage on the load carrying capacity of the pile were investigated using this FE model.

\section{Testing of the concrete pile using DFOS}

\subsection{DFOS technology}

DFOS technology measures strain and temperature variations using back-scattered light along the length of fiber optic cables, which act as a continuous series of closely spaced sensing points. As light travels through the optical fiber, Brillouin scattering is caused by the interaction of the incident light wave photons with propagating density waves or acoustic vibrations (phonons). These acoustic vibrations are affected by density and refractive index fluctuations induced by temperature or strain changes [25]. The Brillouin scattering is inelastic and the photons may lose or gain energy (Stokes and anti-Stokes processes) and create or absorb phonons. This shift in photon energy corresponds to a shift in the frequency of the scattered light wave, which is referred to as the Brillouin frequency shift. A change in strain $(\Delta \varepsilon)$ or temperature $(\Delta T)$ at any point along the optical fiber is equivalent to a relevant shift in the Brillouin frequency $\left(\Delta v_{\mathrm{b}}\right)$ at that location, which can be detected using Brillouin optical time domain reflectometry (BOTDR). Under normal environmental conditions, this frequency shift varies with changes in longitudinal strain and temperature in the fiber core/cladding [26,27]:

$$
\Delta v_{\mathrm{b}}=C_{\varepsilon} \Delta \varepsilon+C_{\mathrm{T}} \Delta T,
$$

where $C_{\varepsilon}$ and $C_{\mathrm{T}}$ are the strain and the temperature coefficients of the Brillouin frequency shift for the DFOS cables, which were $497 \mathrm{MHz} / \%$ and $0.96 \mathrm{MHz} /{ }^{\circ} \mathrm{C}$ in this study, respectively.

As discussed above, the Brillouin frequency is affected by both temperature and strain variations. To distinguish between these two effects, a separate temperature compensation cable is typically installed adjacent to the strain cable. The temperature compensation cable is constructed with an inner gel-filled tube hosting single mode optical fibers. In this gel-filled loose tube cable the frequency change $\Delta v_{\mathrm{b}}$ is affected by the temperature variations only. Hence, temperature changes, $\Delta T$, can be obtained from the frequency shift in this temperature cable independently. After substituting into Eq. (1), strain changes can be calculated using the Brillouin frequency change measured in the strain cable.

\subsection{Pile testing and instrumentation}

In this study, a static maintained load test was performed on a CFA test pile in London. The purpose of this test was to investigate the strain and settlement of the pile under different vertical compressive loads, which defines the load-carrying capability of the pile for a range of displacements.

The design length of the test pile was $25 \mathrm{~m}$ with a nominal diameter of $900 \mathrm{~mm}$ and a reinforcement cage diameter of $750 \mathrm{~mm}$, as shown in Fig. 1. This test pile included a $20 \mathrm{~m}$ long reinforcement cage and $25 \mathrm{~m}$ long central reinforcement bar bundle, such that the upper $20 \mathrm{~m}$ of the pile were reinforced with both cage and bar bundle, while the lower $5 \mathrm{~m}$ of the pile were reinforced only with the central bar bundle. The soil stratigraphy in the testing area consisted of made Ground, alluvium, River Terrace, and Lambeth Group clay.

To measure the strain along the whole depth of the pile during load testing, the DFOS cables were installed on the cage in U-shaped loops (Fig. 1). Each loop consisted of two FO cables: a loose-tube temperature cable, and a tightly-bonded strain cable, with the latter being prestrained by hand before being fixed in place on the reinforcement. The temperature cable was used for temperature compensation of the strain measurement. The two cables were fixed to the pile reinforcement at the top and bottom, and held loosely along the reinforcement with intermediate cable-ties to prevent cable deflection during concrete pouring. A similar DFOS cable pair loop was also installed on the central bundle of reinforcement bars. Further details about the instrumentation in this pile is provided by de Battista et al. [28].

A Yokogawa AQ8603 BOTDR spectrum analyzer was used to take readings of Brillouin frequency from the DFOS cables. The spatial resolution of the analyzer was 1 $\mathrm{m}$ and the sampling resolution (the distance between two consecutive sampling points digitised by the analyzer) was $0.1 \mathrm{~m}$. Hence, each instrumented $20 \mathrm{~m}$-long side of the pile cage provided 200 data points of strain and temperature measurements.

During the load test, a controlled load was applied and removed in stepped stages from a loading frame above the pile, as shown in Fig. 2. The test pile was subjected to maintained loading in axial compression, consisting of two staged cycles of applied load up to 11.4 and $20.0 \mathrm{MN}$. The load was applied in discrete increments, as shown in Fig. 3. Each load increment was applied when the settlement rate of the pile was below the specified criteria. This static load test lasted approximately $60 \mathrm{~h}$. At each loading and 

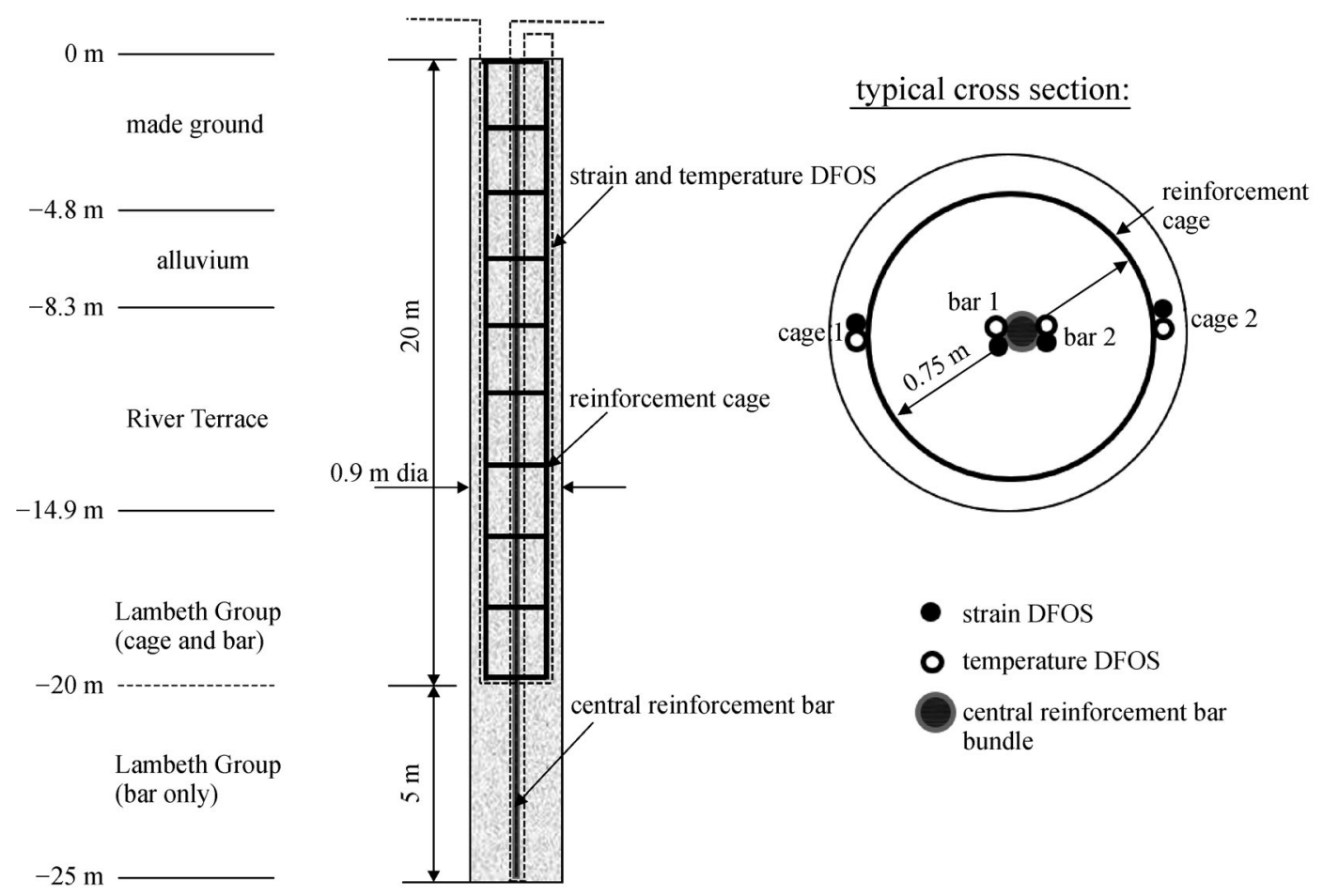

Fig. 1 Distributed fiber optic sensor cables installed in the CFA pile.

unloading stage, the applied load and displacement at the pile head were measured using a load cell and linear variable differential transformers (LVDTs), respectively. From these, the load-settlement relationship of the pile was derived.

\section{Data analysis}

Figure 4 shows the strain profiles measured by DFOS during some of the load stages, from 7.7 to $20 \mathrm{MN}$. A maximum compressive strain of about $800 \times 10^{-6}$ was recorded close to the top of the pile, under a load of $20 \mathrm{MN}$.

A sudden reduction of strain in the pile was observed in the alluvium and River Terrace Deposits strata, when compared with the expected gradual decrease in strain. This is likely caused by a larger pile cross-section at these depths, and hence a smaller strain for a given load, which is indicative of an overbreak at these depths. In addition, the four strain profiles in each load stage are quite similar except in the made ground stratum. This indicates that the pile had a fairly symmetric cross-section throughout its depth, and hence the strain profiles on different sides are quite similar. However, some fluctuations in the pile strain appear in the top part of the pile. This could be due to cross-sectional irregularities close to the pile head.

The similarity in the measurement results between the four cables highlights the reliability and repeatability of DFOS. This is considering that the measurement and temperature compensation for the four different distributed fiber optic cables are independent. In addition, each cable provided hundreds of data points. These data points produced a series of similar and relatively smooth curves under various loading conditions, which further validate the repeatability of the measurements.

At each loading stage, the settlement at the pile head was measured by LVDTs. By integrating the head settlement and average strain profile from top to bottom, the axial displacement of the pile along the whole depth can be calculated, as shown in Fig. 5. Under the static load of 20 $\mathrm{MN}$, the maximum settlement close to the pile head was about $35 \mathrm{~mm}$. This settlement decreased gradually with pile depth, due to the compression of the concrete pile. At the pile tip, this value was about $23.5 \mathrm{~mm}$, which indicates that a portion of the axial load had been transferred to the pile tip. A number of design parameters can be estimated from the strain and displacement data, such as the pile modulus at the pile head, the shaft friction for the different soil strata, and the pile tip resistance [30].

\section{FE analysis}

To further investigate the performance of the test pile under static loading, a FE analysis was performed. The pile load test was simulated by a simple 1D load-transfer FE model. As illustrated in Fig. 6, the vertical axially-loaded pile was simplified as a series of linear elastic axially loaded 


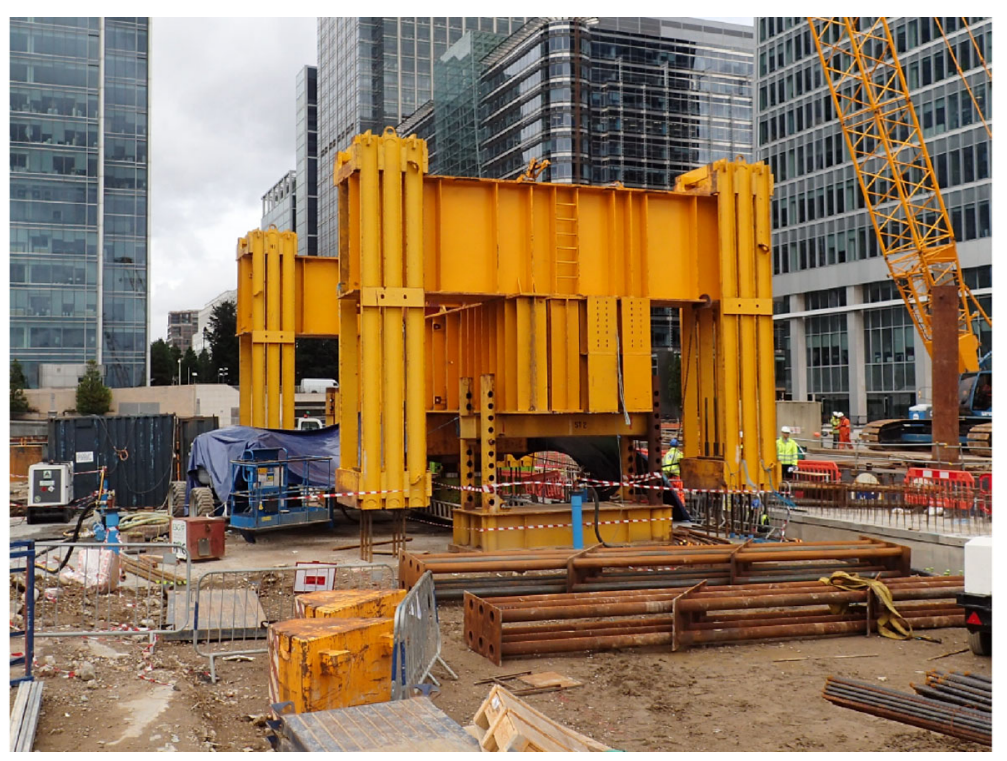

Fig. 2 Static load testing frame for the trial test pile (reproduced from de Battista et al. [29] with permission).

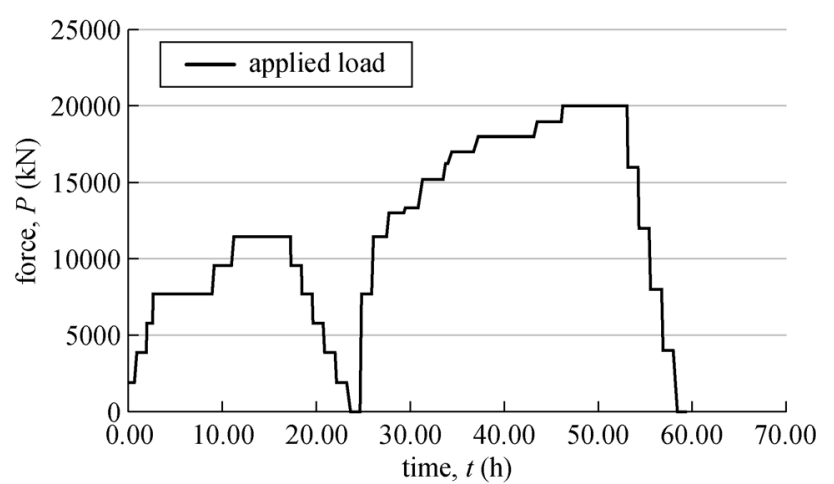

Fig. 3 Pile load test schedule.

elements and a the pile-soil interaction was modeled as a series of nonlinear soil springs, both of which had vertical displacement degrees-of-freedom only. This simplification avoids having to mesh the cross section of the pile. This means that the modeled variables, including displacement, strain and stress are averaged across the pile's cross section and vary only along the length of the pile. This model contained 250 axially loaded elements with uniform mesh size.

The behavior of the soil springs for shaft friction and tip reaction was simulated by the nonlinear load-transfer curves [30]. The shear stress $t$ and tip resistance $q$ can be written as:

$$
t=\frac{k_{\mathrm{m}}}{\sqrt[d]{\left(1+\left(\frac{k_{\mathrm{m}}}{t_{\mathrm{m}}} z\right)^{h d}\right)}}
$$

$$
q=\frac{k_{\mathrm{m}}}{\sqrt[d]{\left(1+\left(\frac{k_{\mathrm{m}}}{q_{\mathrm{m}}}\right)^{h d}\right)}}
$$

where $k_{\mathrm{m}}$ is the maximum stiffness, $t_{\mathrm{m}}$ is the maximum shear stress, $q_{\mathrm{m}}$ is the maximum tip resistance, $d$ and $h$ are the material constants which control the hardening and degradation behavior, and $z$ is the vertical displacement.

According to the static equilibrium in the vertical direction:

$$
t \cdot 2 \pi r \mathrm{~d} z=E \cdot \pi r^{2} \mathrm{~d} \varepsilon
$$

and hence:

$$
t=\frac{E r}{2} \cdot \frac{\mathrm{d} \varepsilon}{\mathrm{d} z},
$$

where $r$ is the pile radius, $\varepsilon$ is the pile axial strain, and $E$ is the concrete Young's modulus. In this case study, $E=40$ $\mathrm{GPa}$ for concrete and uniform $r=0.45 \mathrm{~m}$.

According to Eq. (5), the shaft friction can be calculated directly from the observed axial strain from the DFOS, and the results for different soil strata are plotted in Fig. 7. Similarly, the tip resistance $q$ can also be calculated from the pile strain:

$$
q=E \varepsilon_{\text {bot }},
$$

where $\varepsilon_{\mathrm{bot}}$ is the axial strain at the pile tip.

The Young's modulus of pile concrete can vary significantly from the value given in the codes or obtained from the laboratory tests [30]. The static load applied on the pile head, $F$, can be written as: 


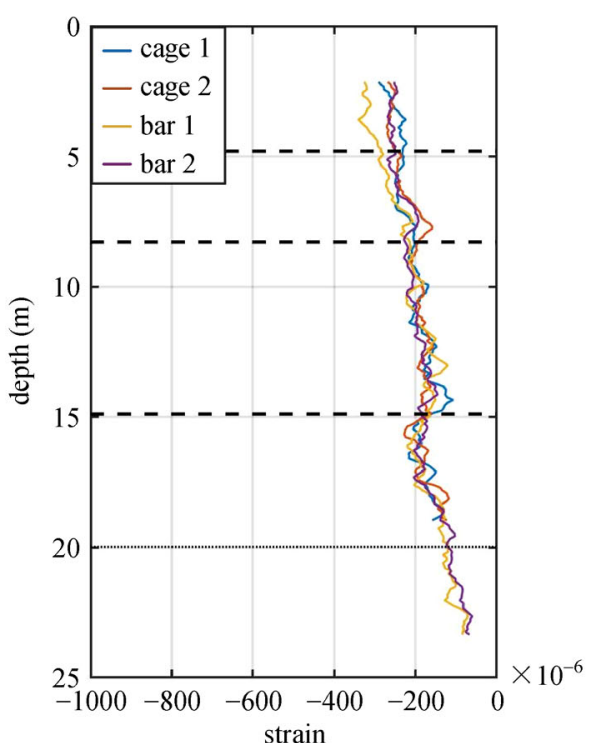

(a)

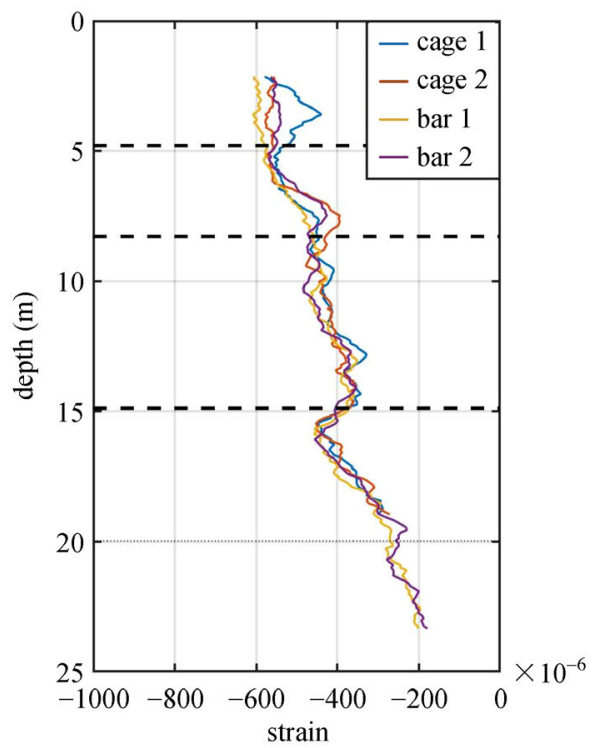

(c)

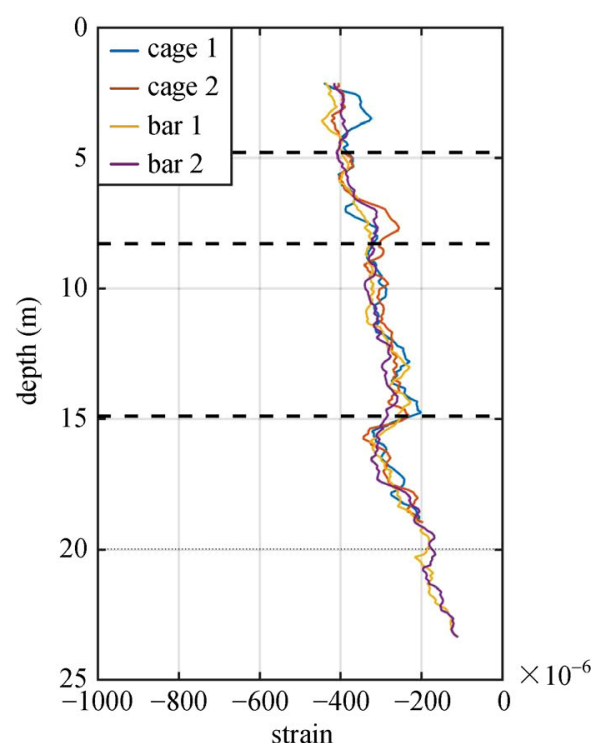

(b)

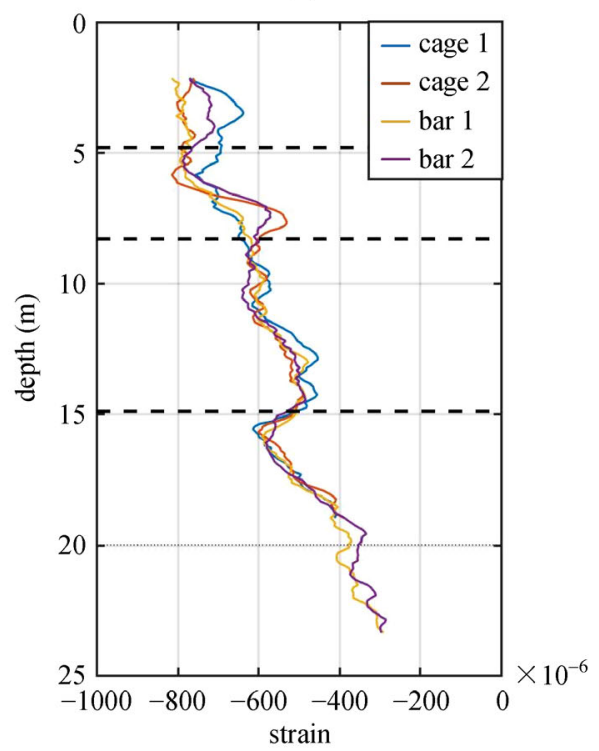

(d)

Fig. 4 Strain profile of the CFA pile, as it was incrementally loaded vertically in compression, with loads of (a) $7.7 \mathrm{MN}$, (b) $11.4 \mathrm{MN}$, (c) 15.2 MN and (d) 20.0 MN (negative strain indicates compression).

$$
F=E \cdot \pi r^{2} \varepsilon_{\text {top }}
$$

where $\varepsilon_{\text {top }}$ is the axial strain at the pile head. Hence, the value of Young's modulus can be back calculated according to $F$ and $\varepsilon_{\text {top }}$ measured at each loading stage. The field test data show that the real young's modulus at the pile head was close to $40 \mathrm{GPa}$.

The load transfer curves were calibrated by the shaft friction derived from the DFOS strain, as shown in Fig. 7. The relative displacement and shaft friction are average values for each strata with reference to the initial stage. The axial strain used was the average strain recorded by the four FO cables in the pile. Because the DFOS can provide a high spatial density of axial strain during the loading test, hence the shaft friction with $0.1 \mathrm{~m}$ intervals can be calculated using Eqs. (5) and (6). In the calibration, the average shaft friction for each strata was used. Accordingly, the parameters in the spring model can be calibrated for each strata, as listed in Table 1 . The results showed that the nonlinear load-transfer curves matched the observed data very well.

The large difference between Figs. 7(d) and 7(e) indicates the reinforcement cage had a significant effect on the load-transfer between the pile and the surrounding soil, for the same soil stratum (Lambeth Group). With the reinforcement cage, the maximum shaft friction reached about $360 \mathrm{kPa}$. But with the reinforcement bar bundle only, this value decreased sharply to about $110 \mathrm{kPa}$. This is 


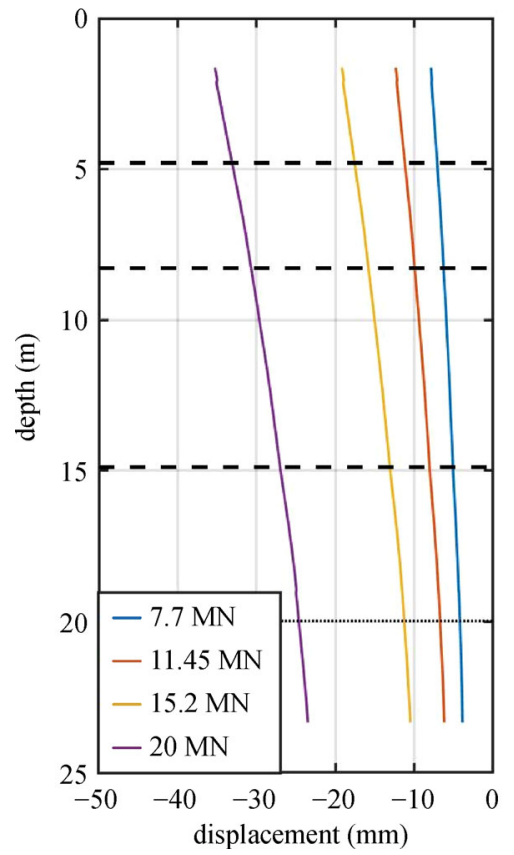

Fig. 5 Displacement profile of the CFA pile (negative displacement indicates settlement).

because the reinforcement cage increases the stiffness of the concrete pile, especially at the pile surface close to the soil. This increase in pile stiffness would also increase the load transfer, and hence a higher shaft friction would be observed in the presence of a reinforcement cage.
Figure 8 shows the pile head settlement from both the FO and FE models. The results showed that the monitoring data matched well with the simulation data. Small differences were observed when the load was between 5 and $15 \mathrm{MN}$, which indicate that the shaft friction was slightly underestimated (hence overestimated pile head settlement) in the FE model during these loading stages.

Figure 9 shows the monitored (DFOS) and calculated (FE) pile axial strains. The monitored strain is the average value of the four cables shown in Fig. 4. A good match is observed in general between measured and calculated strains. However, the FO cables recorded higher values of strain compared to the FE model at depths of 6 and $16 \mathrm{~m}$. This is unexpected when the pile is assumed to be uniform as in the FE model. On the other hand, this difference of pile axial strain was proportional to the applied static load. Hence, this is likely due to localized necking of the pile (smaller cross-section) or decrease in the concrete Young's modulus, both of which would result in a localized increase of strain for a given load. From a parametric study, it was found that, if the compressive stiffness (EA) decreased by about $13 \%$ at depth of $6 \mathrm{~m}$ and $16 \%$ at depth of $16 \mathrm{~m}$, a good match could be obtained between the measured and simulated pile axial strains.

Turning points in the measured and simulated axial strain profiles were observed at the depth of $20 \mathrm{~m}$, coinciding with the bottom of the reinforcement cage. This further indicates the important role of the reinforcement cage in the pile-soil load transfer.
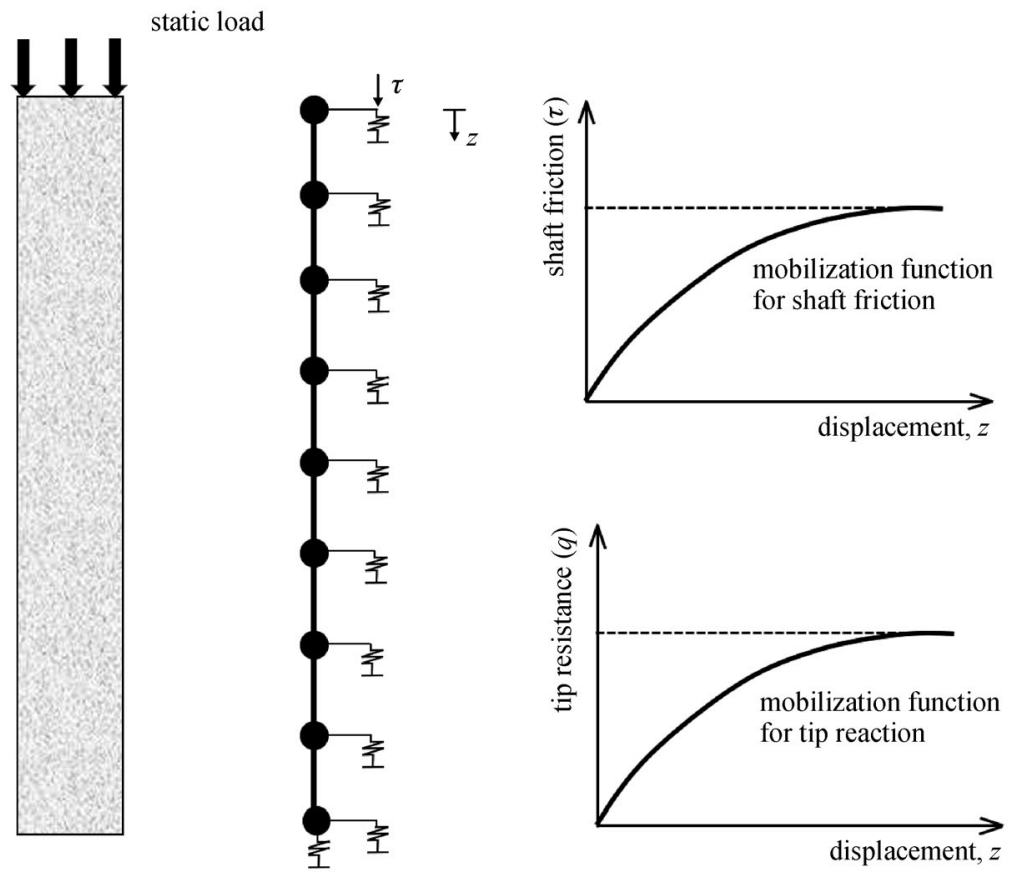

Fig. 6 Load-transfer model. 


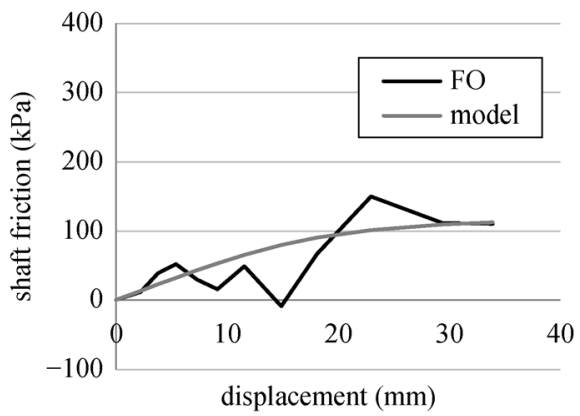

(a)

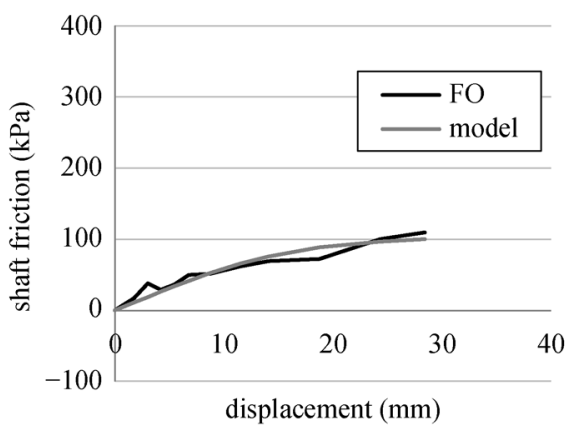

(c)

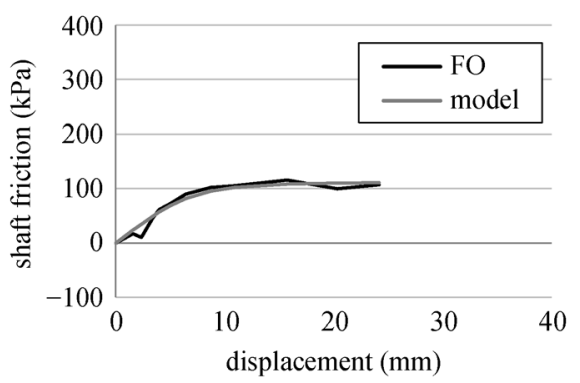

(e)

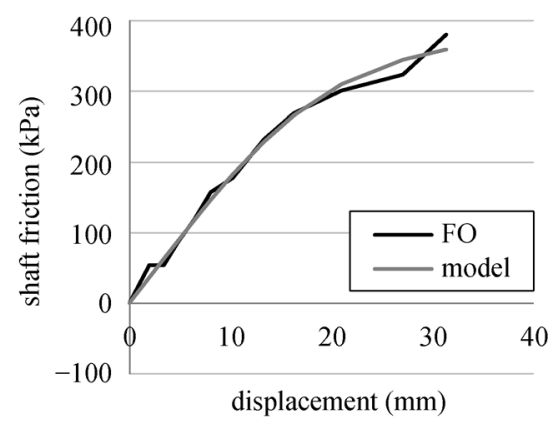

(b)

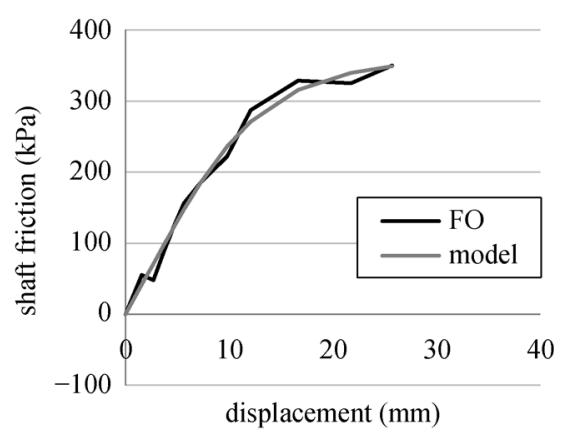

(d)

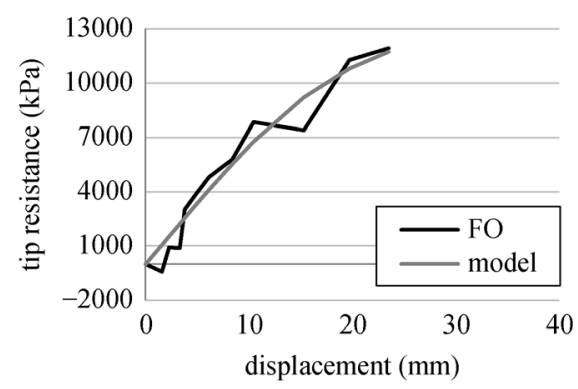

(f)

Fig. 7 Calibration of load-transfer curves: (a) made ground; (b) alluvium; (c) River Terrace; (d) Lambeth Group (cage and bar); (e) Lambeth Group (bar only); (f) tip.

\section{Performance of reinforcement cage and central reinforcement bar bundle}

To investigate the performance of the reinforcement cage and central reinforcement bar bundle in pile load testing, a parametric study was performed based on the three different simulated pile configurations, as shown in Fig. 10. The first pile was identical to the test pile discussed above. The second pile was the top $20 \mathrm{~m}$ part of pile 1 (i.e., the part that had both cage and central bar bundle reinforcement). Pile 3 was $25 \mathrm{~m}$ long with the reinforcement cage and central bar bundle over the whole length. The load-transfer curves for pile 1 and pile 2 were assumed to be identical to those in Table 1. For pile 3, the load transfer in the lower part of the Lambeth Group stratum followed the model of Lambeth Group (cage and bar) in Table 1.
Figure 11 shows the load-settlement curves for these three simulated piles. A linear relationship between the

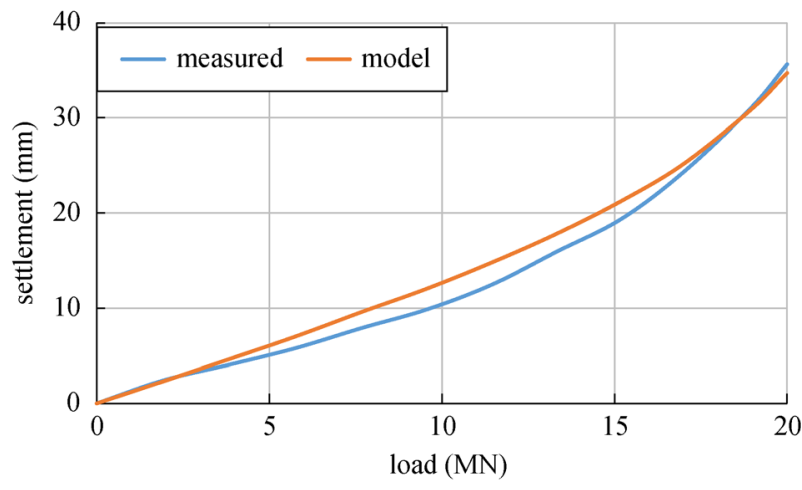

Fig. 8 Comparison of pile head settlement from the FO and FE models. 


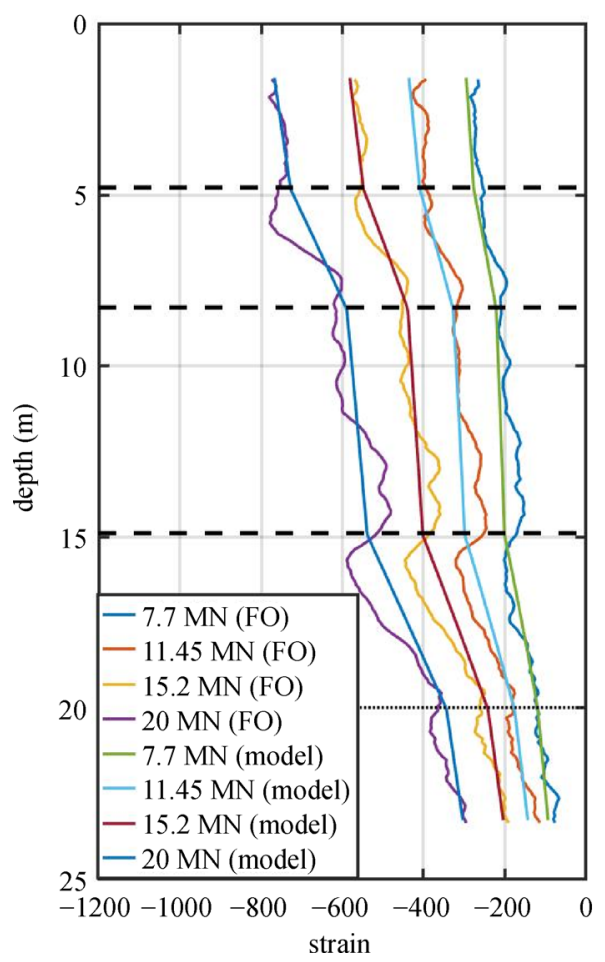

Fig. 9 Comparison of pile axial strains from the FO and FE models. settlement and load under a small load was observed for all three piles. When the load was over $10 \mathrm{MN}$, the pile settled much faster as the load increased. The settlement of pile 1 was always between that of piles 2 and 3 for all loads. The largest settlements of piles 1,2 , and 3 were approximately 35,43 , and $28 \mathrm{~mm}$, respectively, under the static loading of $20 \mathrm{MN}$. This indicates that extending the reinforcement cage to the bottom of the pile (pile 3 ) would result in a $20 \%$ reduction in the pile settlement (from 35 to $28 \mathrm{~mm}$ ) under the maximum applied load, as compared with the test pile investigated in this study (pile 1). On the other hand, removing the bottom $5 \mathrm{~m}$ of the pile which was reinforced only with the bar bundle (as in pile 2) would result in a $23 \%$ increase in pile settlement (from 35 to $43 \mathrm{~mm}$ ).

Figure 12 shows the pile axial strain for the three simulated piles under a load of $20 \mathrm{MN}$. The difference is very small above the depth of $8 \mathrm{~m}$. With the central reinforcement bar bundle only (pile 1), the axial strain decreased faster with depth, as compared with the pile having reinforcement cage and bar bundle (pile 3). This was due to the larger settlement as shown in Fig. 11, leading to greater shaft friction. On the other hand, a larger tip resistance was observed for pile 2. Using Eq. (6), the tip resistance was about 11.2 MPa for pile 1, 12.9 MPa for pile 2, and 8.7 MPa for pile 3. This further indicates that the
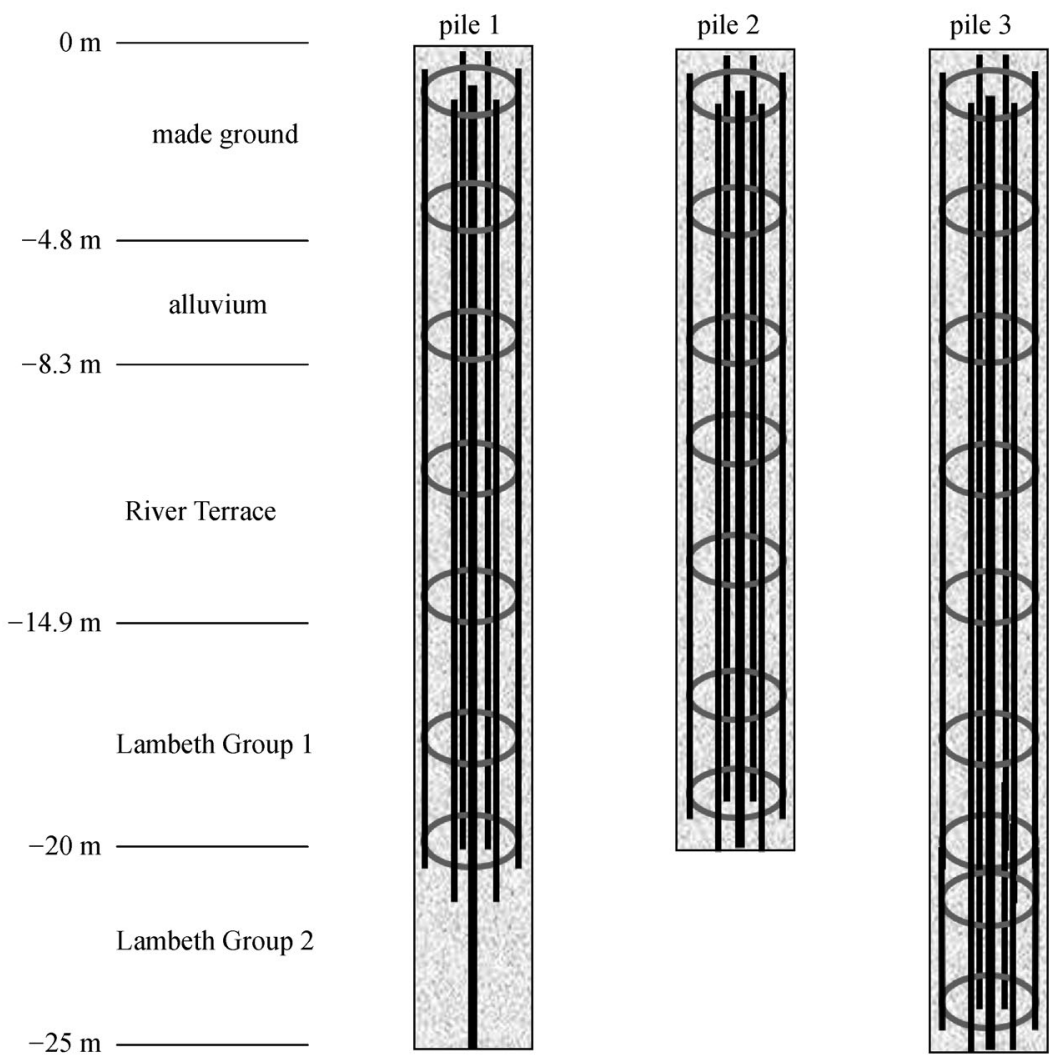

Fig. 10 Assumed differences in the reinforcement cage and bar bundle for comparison purposes in the parametric study. 
Table 1 Calibration parameters of the load-transfer model

\begin{tabular}{lcccc}
\hline layer & $t_{\mathrm{m}}$ or $q_{\mathrm{m}}(\mathrm{kPa})$ & $k_{\mathrm{m}}\left(\mathrm{kN} / \mathrm{m}^{3}\right)$ & $d$ & $h$ \\
\hline made ground & 120 & 6000 & 3 & 1 \\
alluvium & 393 & 18512 & 3 & 1 \\
River Terrace & 107 & 6259 & 3 & 1 \\
Lambeth Group (cage and bar) & 366 & 26632 & 3 & 1 \\
Lambeth Group (bar only) & 112 & 14992 & 3 & 1 \\
tip resistance & 13930 & 674040 & 3 & 1 \\
\hline
\end{tabular}

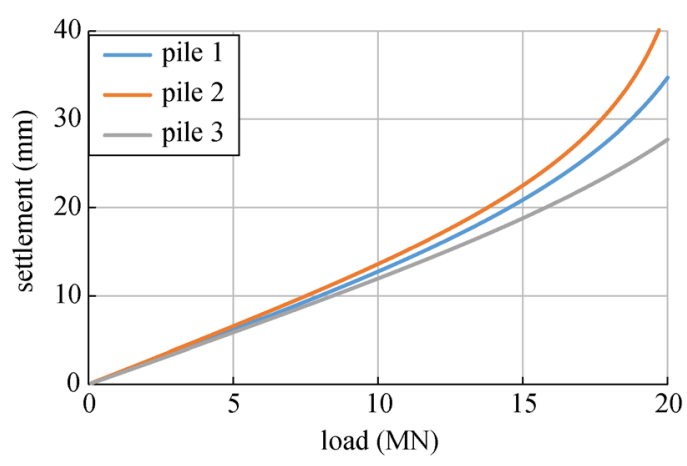

Fig. 11 Pile head settlement.

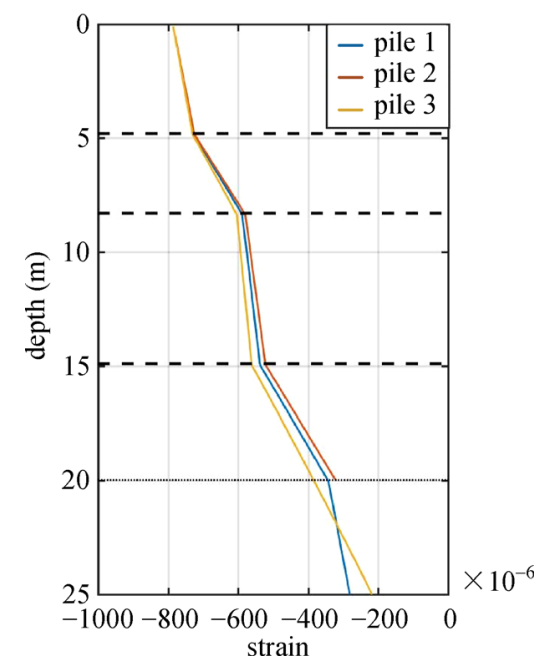

Fig. 12 Pile axial strains under the mechanical load of $20 \mathrm{MN}$.

load carrying capacity of pile 1 was between that of pile 2 and pile 3 .

\section{Conclusions}

In this paper, the application of distributed fiber optic sensor (DFOS) technology was used in full-scale static pile load testing to investigate the integrity and load capacity of a CFA test pile in London. To interpret the monitoring data better, a FE analysis was performed based on a simple 1D load-transfer model. The following conclusions were derived.

1) DFOS provides a high spatial density of measurement data, and hence can give much more information about the properties and performance of a reinforced concrete pile than point sensors. In this case study, some anomalies, like an irregular pile cross-sectional area in the CFA test pile, were identified, which would not have been possible to identify using conventional point sensors. Such a postulation is supported by the comparison between the FO data and $\mathrm{FE}$ analysis.

2) The continuous strain profiles can be used to calculate the pile displacement and shaft friction through numerical integration and differentiation. These can provide information for calibration of the load transfer model used in the $\mathrm{FE}$ analysis.

3) A good match was obtained between the monitoring data and FE analysis in terms of pile axial strain and pile displacement, which indicates that the nonlinear loadtransfer model used in this study was able to simulate the pile and soil performance during the load testing.

4) The performance of the reinforcement cage and central reinforcement bar bundle in pile load testing were investigated through a numerical study. It was found that extending the reinforcement cage to the bottom of the pile (as opposed to having the bottom $5 \mathrm{~m}$ of the pile reinforced only with the central bar bundle) would reduce the pile settlement by up to $20 \%$ under a maximum load of $20 \mathrm{MN}$, as well as increase the load carrying capacity of the pile.

Acknowledgements The authors thank the EPSRC and Innovate UK for funding this research through the Cambridge Centre for Smart Infrastructure and Construction (CSIC) Innovation and Knowledge Centre (EPSRC grand reference number EP/L010917/1). We thank Professor Kenichi Soga (UC Berkeley) for providing valuable input to this research. We would also like to acknowledge the contribution of Angus Cameron from Environmental Scientifics Group.

Open Access This article is licensed under a Creative Commons Attribution 4.0 International License, which permits use, sharing, adaptation, distribution and reproduction in any medium or format, as long as you give appropriate credit to the original author(s) and the source, provide a link to the Creative Commons licence, and indicate if changes were made. The images or other third party material in this article are included in the article's Creative Commons licence, unless indicated otherwise in a credit line to the material. If material is not included in the article's Creative Commons licence and your intended use is not permitted by statutory regulation or exceeds the permitted 
use, you will need to obtain permission directly from the copyright holder. To view a copy of this licence, visit http://creativecommons.org/licenses/by/4.0/.

\section{References}

1. British Standards Institution. BS EN 1997-1:2004 + A1:2013 Eurocode 7. Geotechnical Design, General Rules. London, UK: BSI, 2004

2. Bond A J, Jardine R J, Dalton J C P. Design and performance of the Imperial College instrumented pile. Geotechnical Testing Journal, 1991, 14(4): 413-424

3. Ismael N F. Axial load tests on bored piles and pile groups in cemented sands. Journal of Geotechnical and Geoenvironmental Engineering, 2001, 127(9): 766-773

4. Brown M J, Hyde A F L, Anderson W F. Analysis of a rapid load test on an instrumented bored pile in clay. Geotechnique, 2006, 56(9): 627-638

5. Jardine R J, Zhu B T, Foray $\mathrm{Y} \mathrm{Z} \mathrm{X.} \mathrm{Interpretation} \mathrm{of} \mathrm{stress}$ measurements made around closed-ended displacement piles in sand. Geotechnique, 2013, 63(8): 613-627

6. Jardine R J, Zhu B T, Foray P, Yang Z X. Measurement of stresses around closed-ended displacement piles in sand. Geotechnique, 2013, 63(1): 1-17

7. McNamara A M, Suckling T, McKinley B, Stallebrass S E. A field trial of a reusable, hollow, cast-in-situ pile. Geotechnical Engineering, 2014, 167(4): 390-401

8. Kechavarzi C, Pelecanos L, de Battista N, Soga K. Distributed fibre optic sensing for monitoring reinforced concrete piles. Geotechnical Engineering Journal of the SEAGS \& AGSSEA, 2019, 50(1): 43-51

9. Institution of Civil Engineers (Great Britain). ICE Specification for Piling and Embedded Retaining Walls. London: ICE Publishing, 2016

10. Lee W, Lee W J, Lee S B, Salgado R. Measurement of pile load transfer using the Fiber Bragg Grating sensor system. Canadian Geotechnical Journal, 2004, 41(6): 1222-1232

11. Kister G, Winter D, Gebremichael Y M, Leighton J, Badcock R A, Tester P D, Krishnamurthy S, Boyle W J O, Grattanb K T V, Fernando G F. Methodology and integrity monitoring of foundation concrete piles using Bragg grating optical fibre sensors. Engineering Structures, 2007, 29(9): 2048-2055

12. Majumder M, Gangopadhyay T K, Chakraborty A K, Dasgupta K, Bhattacharya D K. Fibre Bragg gratings in structural health monitoring - Present status and applications. Sensors and Actuators. A, Physical, 2008, 147(1): 150-164

13. Doherty P, Igoe D, Murphy G, Gavin K, Preston J, McAvoy C, Martin C M. Field validation of fibre Bragg grating sensors for measuring strain on driven steel piles. Géotechnique Letters, 2015, 5(2): 74-79

14. Bao X, DeMerchant M, Brown A, Bremner T. Tensile and compressive strain measurement in the lab and field with the distributed Brillouin scattering sensor. Journal of Lightwave Technology, 2001, 19: 1698-1704

15. Cui Q, Pamukcu S, Xiao W, Guintrand C, Toulouse J, Pervizpour M. Distributed fiber sensor based on modulated pulse base reflection and Brillouin gain spectrum analysis. Applied Optics, 2009, 48(30):
5823-5828

16. Cui Q, Pamukcu S, Lin A, Xiao W, Toulouse J. Performance of double side band modulated probe wave in BOTDA distributed fiber sensor. Microwave and Optical Technology Letters, 2010, 52: 2713-2717

17. Cui Q, Pamukcu S, Lin A, Xiao W, Herr D, Toulouse J, Pervizpour M. Distributed temperature-sensing system based on Rayleigh scattering BOTDA. IEEE Sensors Journal, 2011, 11(2): 399-403

18. Pamukcu S, Cetisli F, Texier S, Naito C, Toulouse J. Dynamic strains with Brillouin scattering distributed fiber optic sensor. GeoCongress, 2006, 187: 31-36

19. Cheung L L K, Soga K, Bennett P J, Kobayashi Y, Amatya B, Wright P. Optical fibre strain measurement for tunnel lining monitoring. Proceedings of the Institution of Civil EngineersGeotechnical Engineering, 2010, 163(3): 119-130

20. de Battista N, Elshafie M, Soga K, Williamson M, Hazelden G, Hsu Y S. Strain monitoring using embedded distributed fibre optic sensors in a sprayed concrete tunnel lining during the excavation of cross-passages. In: Proceedings of the 7th International Conference on Structural Health Monitoring and Intelligent Infrastructure (SHMII7). Torino: Curran Associates, Inc., 2015: 1-3

21. Kechavarzi C, Soga K, de Battista N, Pelecanos L, Elshafie M Z E B, Mair R J. Distributed Fibre Optic Strain Sensing for Monitoring Civil Infrastructure. London: Thomas Telford, 2016: 241-246

22. Mohamad H, Bennett P J, Soga K, Mair R J, Bowers K. Behaviour of an old masonry tunnel due to tunnelling-induced ground settlement. Geotechnique, 2010, 60(12): 927-938

23. Rui Y, Kechavarzi C, O’Leary F, Barker C, Nicholson D, Soga K. Integrity testing of pile cover using distributed fibre optic sensing. Sensors (Basel), 2017, 17(12): 2949

24. Schwamb T, Soga K, Mair R J, Elshafie M Z, Boquet C, Greenwood J. Fibre optic monitoring of a deep circular excavation. Geotechnical Engineering, 2014, 167(2): 144-154

25. Garus D, Golgolla T, Krebber K, Schliep F. Brillouin optical frequency-domain analysis for distributed temperature and strain measurements. Journal of Lightwave Technology, 1997, 15: 654662

26. Horiguchi T, Kurashima T, Tateda M. Tensile strain dependence of Brillouin frequency shift in silica optical fibers. IEEE Photonics Technology Letters, 1989, 1: 107-108

27. Kurashima T, Horiguchi T, Tateda M. Thermal effects on the Brillouin frequency shift in jacketed optical silica fibers. Applied Optics, 1990, 29: 2219-2222

28. de Battista N, Kechavarzi C, Soga K. Distributed fiber optic sensors for monitoring reinforced concrete piles using Brillouin scattering. In: Proceedings of the European Workshop on Optical Fibre Sensors-EWOFS 2016. Limerick: SPIE, 2016

29. de Battista N, Kechavarzi C, Seo H, Soga K, Pennington S. Distributed fibre optic sensors for measuring strain and temperature of cast-in-situ concrete test piles. In: Proceedings of the International Conference on Smart Infrastructure and Construction (ICSIC). London: ICE Publishing, 2016

30. Pelecanos L, Soga K, Elshafie M Z, de Battista N, Kechavarzi C, Gue C Y, Seo H J. Distributed fiber optic sensing of axially loaded bored piles. Journal of Geotechnical and Geoenvironmental Engineering, 2017, 144(3): 04017122 